\title{
Supporting assessment and feedback practice with technology: a view of the UK landscape
}

\author{
Dr Gill Ferrell ${ }^{1}$, Marianne Sheppard ${ }^{2}$ \\ ${ }^{1}$ Jisc infoNet, Northumbria University, Hadrian House, Higham Place, Newcastle NE1 8AF, UK, \\ gill.ferrell@northumbria.ac.uk \\ 2 Jisc infoNet, Northumbria University, Hadrian House, Higham Place, Newcastle NE1 8AF, UK, \\ marianne.sheppard@northumbria.ac.uk
}

\section{Keywords}

Assessment, educational principles, feedback, feed forward, formative, Grademark, online submission, online marketing, pedagogy, peer review, peerwise, QTI, self reflection, summative, Turnitin.

\section{ABSTRACT}

Assessment and feedback lies at the heart of the learning experience, and forms a significant part of both academic and administrative workload. In the UK however it remains the single biggest source of student dissatisfaction with the higher education experience. Most providers of higher education are seeking to enhance their approaches to assessment and feedback to better meet learner needs and expectations and are having to do so in the face of increasing resource constraints. The Jisc Assessment and Feedback programme (Sept 2011-Aug 2014) is supporting large-scale changes in assessment and feedback practice, supported by technology, with the aim of enhancing the learning and teaching process and delivering efficiencies and quality improvements.

This paper looks at some of the emerging outcomes of this work. It reviews the assessment and feedback landscape at the start of the programme, highlights some of the most significant issues and looks at the ways in which technology is being applied to enhance practice in each of these areas. In particular the paper highlights some open source tools and other resources that are readily available for use by other EUNIS members.

\section{INTRODUCTION}

Assessment and feedback lies at the heart of the learning experience, and forms a significant part of both academic and administrative workload. In the UK however it remains the single biggest source of student dissatisfaction with the higher education experience. Most providers of higher education are seeking to enhance their approaches to assessment and feedback to better meet learner needs and expectations and are having to do so in the face of increasing resource constraints. The Jisc Assessment and Feedback programme (Sept 2011-Aug 2014) is supporting large-scale changes in assessment and feedback practice, supported by technology, with the aim of enhancing the learning and teaching process and delivering efficiencies and quality improvements.

The programme consists of 20 projects organised under various strands of activity and due to complete their work at different times. The institutions whose project work has contributed to this summary are:

- Bath Spa University partnered by the University of Winchester (

- Cornwall College partnered by Hull College (FAST project)

- University of Dundee(InterAct and EFFECT projects)

- University of Edinburgh (SGC4L project)

- University of Exeter (Collaborate and OCME projects)

- University of Glamorgan (Assessment Diaries and Grademark project)

- University of Hertfordshire (Herts - iTeam and EEVS projects)

- University of Huddersfield (EBEAM project)

- Institute of Education (IOE - Assessment Careers project) 
- Kingston University (Uniqurate project)

- Manchester Metropolitan University (MMU - TRAFFIC project)

- University of Nottingham (Rogō project)

- The Open University partnered by the University of Manchester (OU - eFeP project)

- Queen's University Belfast (QUB - eAFFECT project)

- University of Westminster partnered by University of Bedfordshire, Cardiff Metropolitan University (formerly UWIC), City University, University of Greenwich, University of Reading (MACE Project)

The reader is referred to the assessment and feedback pages in the Jisc Design Studio for a more comprehensive overview of current work on assessment and feedback in the UK and outputs from related projects. The Jisc publication 'Effective Assessment in a Digital Age' also illustrates some of the many excellent examples of good practice that already exist.

\section{THE ASSESSMENT AND FEEDBACK LANDSCAPE}

One of the early activities of the programme was to undertake a detailed review of assessment and feedback practice in eight of the participating universities and to combine this with a literature review to give an overall picture of the assessment and feedback landscape across the UK. A summary of this work has been published (Ferrell 2012a).

This work drew on a growing body of literature and empirical evidence on what constitutes effective support for learning and identified some excellent examples of the innovative use of technology to deliver that support. It found there are some seminal works, such as REAP, (discussed further in section 4) that are influencing thinking right across the sector and there are pockets of good and innovative practice in every institution.

The analysis does however paint a somewhat gloomy picture of practice as a whole reflecting the difficulties inherent in scaling up and embedding the good practice and innovation that exists in these small pockets in every university. Overall, the sector is finding that 'practice remains stubbornly resistant to change.' The main findings of the landscape review include:

- the real responsibility for assessment and feedback is highly devolved within universities and considerable variations in practice give many universities cause for concern;

- formal documentation remains quite technical and procedural in nature and is slow to catch up with the shift in thinking about assessment as a more developmental process for as well as of learning;

- the academic structure of degrees, particularly semesterisation, contributes to assessment of learning and diminishes opportunities for assessment for learning;

- academic staff have too few opportunities to gain awareness of different approaches to/ forms of assessment because of insufficient time and a lack of opportunities to share new practices;

- there continues to be heavy reliance on traditional types of assessment such as essays and examinations in some disciplines;

- considerable efforts are being made to develop practice that feeds forwards into the learner's longitudinal development but academic opinion on approaches to feedback remains divided;

- engagement with employers is causing some institutions to question some of their current practice which does not reflect the ways in which professionals undertake formative development during their careers;

- opportunities for students to engage with assessment design and the process of making academic judgements appears to be limited at present;

- many institutions have made significant investment in the technical infrastructure to support assessment and feedback but this is not yet delivering resource efficiencies due to localised variations in underlying processes;

- institutions are preferring to work with existing/established technologies but are nonetheless finding that innovation projects are difficult to scale up;

- institutions need to develop effective structures to facilitate the sharing of good practice that exists in small pockets across each institution. 
It is against this backdrop that the universities participating in the programme undertook their own enhancement activities. The programme differs from much of Jisc's previous, more narrowly focused, work on e-assessment in that it has much more of an overtly pedagogical focus. In looking at how technology can best support assessment and feedback practice, the projects went back to first principles about precisely what those activities were intended to achieve.

\section{TECHNOLOGY AND EDUCATIONAL PRINCIPLES}

Although it might be assumed that an underlying set of educational principles would form the basis of assessment and feedback strategy and policy in any university, it appears that this is not necessarily the case. Although some universities have high level strategies (learning and teaching strategies are increasingly being renamed learning teaching and assessment) responsibility for assessment and feedback is often devolved to individual faculties, schools and departments and articulation of institutional principles shows considerable concern with issues of procedure and consistency rather than educational design e.g.

- The principles and procedures for, and processes of, assessment should be explicit, valid and reliable.

- That all University processes and procedures for assessment and feedback should be explicit, valid and reliable and all students receive parity of treatment.

- The procedures for marking and for moderating marks must be transparent and fair.

- To ensure that the standard for each award and award element is set and maintained at the appropriate level, and that student performance is properly judged against this.

- Achievable : assessments and assessment regimes should be designed so that the threshold requirements are achievable by any student admitted on to the programme of study

- Gradable : it should usually be possible to grade student performance for a specified assessment using a full range of marks.

- Students should be fully aware of what constitutes academic misconduct and the consequences associated with it.

- Assessment should be conducted with rigour, probity and fairness with due regard to security.

The examples above are tonally and qualitatively different from the principles most often cited as reflecting current thinking and influencing the projects in the programme: in particular the highly influential set of REAP principles developed through the work of Professor David Nicol and colleagues at the University of Strathclyde.

\section{REAP (RE-Engineering Assessment Practices) Principles (www.REAP.ac.uk)}

Assessment tasks should: (engage)

1. Capture sufficient study time and effort in and out of class

2. Distribute students' effort evenly across topics and weeks.

3. Engage students in deep not just shallow learning activity

4. Communicate clear and high expectations to students.

Good feedback practice should:

(empower)

1. Clarify what good performance is (goals, criteria, standards)

2. Facilitate the development of reflection and self-assessment in learning

3. Deliver high quality feedback to students: that enables them to self-correct

4. Encourage dialogue around learning (peer and tutor-student)

5. Encourage positive motivational beliefs and self-esteem

6. Provide opportunities to act on feedback

7. Provide information that teachers can use to help shape their teaching

Facilitating a discourse on educational principles has been an important starting point for many of the projects. By defining the principles that characterise each university, academics, those responsible for quality assurance and administration and learning technologists have been able to work together to look at whether those principles are genuinely reflected in practice and, where 
improvement is required, to move forward on the basis of a shared understanding of what is fundamentally important.

As a result of this work a number of universities have created tools to help them align types of assignments with assessment principles and identify appropriate technologies to support the activities.

Queen's University Belfast has created a set of 'technology cards' evaluating a range of technologies and matching them to particular types of assessment practice.

In thinking about the relationship between technology and assessment, the University of Exeter Collaborate project originally envisaged a series of matrices looking at different aspects such as: potential technologies, available technologies, employability dimensions and current use. The thinking about how best to achieve this has now evolved into the idea of a web-based database that can support different forms of visualisation for different datasets and the use of Google Fusion is being trialled. One output of this work is a series of cards in 'Top Trumps' format rating the technologies against each of the dimensions in Exeter's model of work integrated learning.

\section{THE ASSESSMENT AND FEEDBACK TECHNOLOGY LANDSCAPE}

A wide range of technologies are used to support assessment and feedback in a variety of ways ranging from infrastructure to support the formal processes to tools to improve the learning experience and make assessment and feedback more engaging. Most universities have a variety of technologies at their disposal although it is difficult to establish exactly how widely some of the tools are used. There is also considerable variety in the extent to which the technologies are integrated e.g. most institutions are using plagiarism detection software and some have this integrated with their VLE whereas others do not.

On the whole universities are tending to work with technologies that are already well-established. One institution described its approach as seeking sustainable activity in relation to:

- Using existing technologies

- Using technologies identified as relevant to employer need

- Using technologies considered within reach and which are accessible by tutors and learners

Another summed up much of current thinking about the application of technology: 'A useful approach to selecting technology is outlined by TESTA. This proposes that assessment processes should use readily-available technologies which are quick to learn, easy to use, which are efficient after the start-up period, saving time \& effort and increasing productivity and which bring significant learning benefit to students. However, at the moment there seems to be no agreement as to what software or technology solution that might be.'

Cornwall College found its students tend to be as conservative as staff in relation to the use of technology for formal assessment: 'Currently, of 18 learner PESD module groups examined only 1 group (5.5\%) has opted to deliver the assignment in a format other than a word document. This group opted for a powerpoint presentation. The assignment brief makes clear that students may use a technology of their choice yet it is clear that students elect to stick with traditional platforms/formats.'

Given that many of the projects in the assessment and feedback programme are undertaking initiatives on a large scale, there are clear messages about the need to be confident about the reliability of the technology before rolling out e.g. this was a message relating to the use of EVS (electronic voting systems) in the University of Hertfordshire. The importance both of staff development and the availability of technical support are also noted: 'Attention should however be paid to ensuring that academic staff have sufficient support and opportunities to practice with their use, prior to using EVS in large classes. Increased local and centrally provided technical support for academics and students are both strongly recommended.'

As well as reliability, integration with other core systems appears to be a significant factor in the success of these initiatives. The University of Westminster has received considerable acclaim for its Making Assessment Count ( $\mathrm{MAC}$ ) approach to supporting student self reflection yet the experience of trying to roll out the approach across a number of different institutions has been mixed. Where the pilots were less successful, it appears that the stand-alone nature of the e-Reflect tool used to 
support the approach has been an impediment to wider take-up. A separate project is now developing an LTI compliant version of e-Reflect in order that other institutions can operate the process from within their VLE and benefit from the workflow elements of the current tool.

The University of Glamorgan is also looking to improve integration of its Assessment Diaries with Turnitin and Blackboard in order to avoid duplicate data entry.

A strong message from many universities is that the considerable variation in business processes across different parts of the organisation is an impediment to achieving the full potential of efficiency savings in areas such as online submission and marking.

\section{SUPPORTING A RANGE OF ASSESSMENT TYPES}

A concern at the outset of the programme was the extent to which the bulk of current practice remains firmly rooted in traditional approaches and concentrates on assessment of, rather than for, learning. This type of summative assessment is only one of many types covered in the programme. Others include:

- summative

- formative

- authentic

- ipsative

Awareness, and understanding, of the full range of forms appears however to be limited amongst many academic staff. One university noted that, 'Although formative assessment is now more widely recognised than it has been in the past, even that is still at an early stage of adoption.' and very often only summative assessment is incorporated into formal institutional procedure.

The term authentic assessment is increasingly used to describe assessment related to the world of work. The term is however a contentious one and other terms used for work-related assessment include: integrated, work focused, experiential, work-related, contextual, and situated assessment.

Ipsative assessment is a form whereby feedback acknowledges progress against the learner's previous performance regardless of achievement (Hughes et al 2010). The Institute of Education is building upon previous work in this area and looking to develop the concept of an 'assessment career'.

The selection of assessment types is an area where institutions appear to be receiving pressure from students to introduce more variety/authenticity as these comments from students illustrate:

- 'Should have more assessment methods e.g. on-line EMI questions and recognise more practical experience. $100 \%$ Writing essays is not a very good variation in assessment methods!'

- 'The course is very essay based and this makes it feel really onerous. It also does not suit my style of learning. I would prefer some organised sessions, workshops etc and for the written format to be more short answer question or other.'

- 'There is too much emphasis on essays which becomes very boring and repetitive. I have seen others e.g. Cardiff using online material and interactions and therefore improving the course's accessibility.'

One institution identified that overall there were 93 different types of assignment in use across the institution but that new ideas and good practice were slow to spread between disciplines.

Many of the projects are realising that in order to address some of the issues they have identified they need to look at the whole area of curriculum design '... we recognise that for a longitudinal and developmental approach to assessment to succeed, the over-reliance on essays or long written assignments may need to change because these assignments may not help learners develop $M$ level academic thinking and writing approaches over time.' Others are taking a more pragmatic view that, rather than look at curriculum redesign, they need to provide support in order to ensure more effective and efficient practice in relation to the more frequently used types of assessment e.g. 'What are the most effective ways of giving feedback on essays? What kind of feedback can be provided on tests and exams? How long should feedback on presentations take to deliver? How can teams verify that their practice is inclusive?' 
A range of technologies are being used very effectively to support all of these different types of assessment. A couple of examples are given below:

The University of Nottingham has developed an open source assessment management tool, known as Rogō, that can be used for both formative and summative assessment. The product is scalable, secure, re-useable and extensible and is already in use in a range of partner universities. The University of Nottingham is keen to encourage the growth of this community beyond the Englishspeaking world and they are already working with partners in the Czech Republic.

Kingston University Uniqurate project has produced a user-friendly authoring tool to develop assessment material that complies with the QTI 2.1 open standard. This means the resources are readily transferable to a variety of delivery platforms unlike e-assessment content developed in commercial the VLEs or tools such as QuestionMark Perception. The Uniqurate tool avoids the need for the technical expertise needed to author e-assessments inn QTI XML format and provides the means to create complex, adaptive resources that go far beyond the ubiquitous multiple choice questions that commonly come to mind when e-assessment is discussed. Again the tool is available to other universities and can be used for both formative and summative assessment.

\section{USING TECHNOLOGY TO IMPROVE ASSESSMENT PROCESSES}

A 'modelling tool' that has proven useful in reviewing assessment practice, and particularly identifying issues with the overall assessment timetable, is the concept of assessment timelines as developed by the ESCAPE project at the University of Hertfordshire. This is used to model patterns of high medium and low stakes assessment across a 12 week semester. An example is shown below:

\section{A typical example of assessment:}

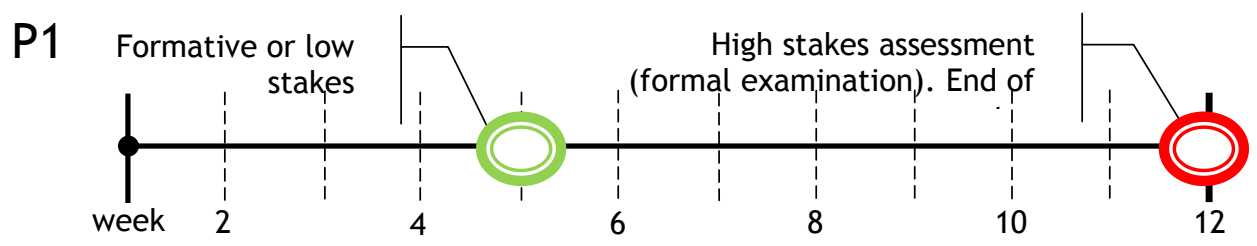

One institution that undertook this type of modelling across a number of disciplines identified that some subject areas exhibited a significant reliance on end of semester high-stakes assessment that did not offer opportunities for formative feedback. This is by no means unusual and was indeed the rationale for developing the tool in the first place.

As well as having pedagogical implications, the frequent emphasis on summative assessment towards the end of the teaching programme has implications for the workload of both students and staff as well as the supporting processes. Manchester Metropolitan University has undertaken some modelling from its coursework submission database and identified significant peaks in assignment submissions (the highest being around 17,000 individual submissions due at the end of March 2012). Even where such peaks are well-managed to the extent that individual learners do not have multiple assignment deadlines falling at the same time, they have major implications for academic and administrative staff workload.

The University of Glamorgan has been addressing a similar issue through its work on Assessment Diaries aimed at reducing the 'bunching' of assessments for students and staff and also providing clear deadlines for feedback. The project revealed the need for dialogue around the setting and publication of deadlines as well as useful feedback from students as to the points at which reminders are most useful to them although an unexpected outcome from some academic staff interviews was a concern that providing such reminders to students inhibited their development of self-directed and autonomous learning skills. This was balanced by the views of some academics who found the tool useful in managing their own workload.

The baseline report noted the value to many projects in using The University of Glamorgan also evaluated its use of GradeMark and identified efficiency savings across the entire assessment and feedback process. It noted however that academic staff tend to focus on the actual time taken to mark a script and require prompting to think about the timescale for the entire process including 
tracking student submissions, using lecture time to hand back the assessments or having multiple interruptions from students collecting marked work at different times. Only a minority of academic staff reflected on the entire process: 'I think the whole process is quicker. We used to rely on the faculty administrators to collect the work and then we have to collect them a few days later and ask the student to come and collect their work. With Turnitin the whole process is a lot quicker. Students do not lose their work. Whether the "marking" is faster I think depends on each individual and it will be different. But the whole process is definitely quicker.'

The extent to which processes for submission and marking of assignments are standardised and/or supported by technology again varies widely. One institution has a coursework recording system which is used to create personalised assessment schedules for each student for the academic year and deal with assignment handling. In the same institution however, 'Marking of coursework is carried out by unit teams according to their own arrangements and criteria and there is no institutional level oversight of the process.'

The University of Exeter is implementing an Online Coursework Management Project with the ultimate aim of creating an institution-wide end to end electronic assessment solution to replace current paper submission, marking and feedback of student assignments.

In other institutions the entire process design is left very much to local discretion even though the institution may have the infrastructure to support a more standardised approach.

Issues around electronic submission and marking (often conflated although they are very different propositions) have been around for many years and show few signs of becoming less contentious. One institution notes: 'For work which is based on the written word, there is a large variation in practice across the institution in terms of procedures for submission and marking. One faculty takes in all work for part-time postgraduates electronically, to reduce the need for students to come specially to campus, but administrative staff then print it all out for marking.' and gives health and safety concerns around online marking as the reason for this.

In the same institution there are examples where course teams are happy with electronic submission but students have to submit a paper copy as well to meet the requirements of the coursework receipting system. In yet another department double submission is required because academics wish to mark using a paper copy but also require an electronic copy to be submitted through the plagiarism detection system.

Queen's University, Belfast has seen significant process change as a result of combining an appreciative enquiry approach with demonstrating the benefits of the application of technology. One School piloted online marking across three modules and, as a result of the pilot participants sharing their experiences with colleagues, the School has taken a decision to move to fully online marking next year. Pivotal in the decision were the views of one academic who was strongly reticent prior to participating in the pilot but found the experience very positive. The benefits identified by that pilot were very influential in persuading the Education Committee of a different School to adopt online submission of coursework through the VLE for 2012/13. 'The implications of this are that staff sharing positive experiences can be a powerful means of bringing about change in practice and process.'

However, even where institutions are making good progress in developing and implementing online systems, there appear to be difficulties to be resolved in handling assignments that are not based on paper/written word and this is an area where more research and examples would be valuable.

\section{TECHNOLOGY SUPPORTING FEEDBACK AND FEED FORWARD}

Feedback provides information to learners about where they are in relation to their learning goals, enabling them to evaluate their progress, identify gaps or misconceptions in their understanding or knowledge and take remedial action. Generated by tutors, peers, mentors, supervisors, a computer, or as a result of self-assessment, feedback is a vital component of effective learning.

Feed forward is as important to learners' progress as feedback. While feedback focuses on a learner's current performance (and may simply justify the grade awarded), feed forward looks ahead to the next assignment, offering constructive guidance on how to do better in future work. A combination of the two ensures that assessment has an effective developmental impact on learning. 
Both of these elements are only effective in supporting learning if they are received in a timely fashion so that further action can be taken (point illustrated by the use of the assessment timelines discussed above).

The landscape review identified a number of issues relating to feedback that need to be addressed:

- consistency

- timeliness

- supporting longitudinal development

For many institutions achieving a shorter turnaround time is therefore crucial. As one institution stated: 'There may be situations where students might accept a trade-off between the quantity of feedback and the time it takes to produce, but in other cases rapid feedback may be more important than great detail.' Another noted that: 'There may be a trade off between the rapidity and quality of feedback so that, for example, imperfect feedback from a fellow student provided almost immediately may have much more impact than more perfect feedback from a tutor four weeks later.'

Institutions are looking at both technical and non-technical solutions to the problem and it has been suggested that disaggregating grades and feedback might be beneficial in a variety of ways: 'Delays to feedback on marked assignments limit learning for students and disaggregating grades and feedback might be a solution. This would enable first markers to send provisional feedback to students as soon as a piece is marked rather than waiting until grades have been agreed and sent to the Examination Board. .... Grades can have a negative influence on learner response to feedback and this is another reason for disaggregation. The process could be automated to improve the speed of delivery of feedback to students.'

Related to both of the above issues is the extent to which feedback supports the ongoing development of the individual learner by feeding forward into their future learning. '... an underlying problem with many assessment regimes [is] that assessments are undertaken on a piecemeal basis and that there is little continuity. Feedback tends to focus on the immediate task and not surprisingly does not routinely include feed forward to future assessment.'

As part of the InterACT project, the University of Dundee carried out a feedback audit in relation to its postgraduate online distance learning programme in medical education. Its baseline review had highlighted the extent of variability in practice and the audit helped quantify the quality and extent of that diversity. A sample of feedback given in 2011 (140 assignments) was audited using a coding framework defined for this purpose. It identified that $95 \%$ of feedback was content related and $72 \%$ related to the immediate task. An interesting contrast to findings at the IOE (discussed below) is however that positive and negative comments were equally balanced $(51 \%$ and $49 \%)$. The audit was originally intended to inform the development of the new process but will now be repeated, on a before and after basis, to compare with feedback given following the implementation of a revised process.

The Institute of Education is taking a similar approach and has developed a feedback profiling tool which serves the dual purpose of developing the feedback approach of staff leading its pilot activities and also providing evidence of change. Analysis shows that praise statements are the commonest element of summative feedback; there is little advice given and that advice is short rather than longer term. It already seems however as though the very development of the tool is acting as a catalyst for change 'Another important lesson learned is that the pilot leaders have not had opportunities in the past to reflect on why and how they give feedback to learners. Helping with the design of the feedback profiling tool has initiated discussion about feedback and several pilot leaders are already rethinking how they write feedback.' (IOE)

The e-Feedback Evaluation Project (eFeP) based at the Open University and the University of Manchester is also analysing written and audio-recorded forms of electronic feedback and will add an interesting additional component to the programme knowledge base when it reports in July 2013 as it is also looking at some student peer to peer feedback.

The University of Glamorgan evaluated its use of GradeMark, an online marking tool that forms part of the Turnitin plagiarism software. The project team views GradeMark as a tool that can significantly improve student and staff assessment experiences by facilitating better management of the feedback process and offering students and staff a tool through which to discuss assessment and 
feedback. The project has conducted a thorough evaluation in which it concludes that students are fairly open about how they receive feedback initially but that their future perceptions and expectations are coloured by the experience of online feedback. The project team notes: ' It was interesting to see that the improvements students suggested were more from a pedagogical perspective in terms of the quality of feedback and their engagement with that feedback.'

Learners require multiple sources of feedback/forward and one of the skills for learners to acquire is how to balance all these. Tools such as e-portfolios for recording reflections, plans, actions, achievements etc can assist in this process and help manage support across multiple modules/tutors.

One innovative use of technology worth highlighting is that as part of the OU/Manchester eFeP projects, a sample of students are using Jing screencasts to give their tutors 'feedback on feedback'. Although there have been evaluations of the use of screencasts for tutor feedback, its use by students themselves is a new development.

\section{SUPPORTING SELF AND PEER REVIEW}

Tutor feedback is only one type of feedback that may support the learning process. Both self reflection and peer review are equally, if not more, important in learning.

The University of Dundee is making a particular effort to promote self feedback, reducing the reliance on 'transmitted' tutor feedback which can lead to dependence on the tutor for information about progress, and to ensure that feedback is also feeding forward into student's longitudinal development. Students on the postgraduate online distance learning programme in medical education a revised process in which they are required to submit a (compulsory) cover sheet with each assignment reflecting on how well they think they have met the criteria and indicating how previous feedback has influenced this assignment. Following feedback from the tutor they are then invited to log onto a wiki (this is optional) and include a reflection on the following four questions:

1. How well does the tutor feedback match with your self-evaluation?

2. What did you learn from the feedback process?

3. What actions, if any, will you take in response to the feedback process?

4. What if anything is unclear about the tutor feedback?

The intention is to create a dialogue and avoid what Boud \& Molloy (2012) term a tendency for 'deflection' when there is a discrepancy between learners' internal perceptions (self-evaluation) and the external teacher's perceptions (feedback). The response to the introduction of the cover sheet has so far been positive from staff and students and has generated interest in other parts of the University.

The MACE project, led by the University of Westminster, is evaluating the application of a Making Assessment Count (MAC) approach across a range of different institutions. The MAC approach is intended to promote student self reflection to enhance learning and uses a range of simple technologies in an integrated process that collates feedback, guides student reflections and facilitates their use of feedback to improve performance. The project will complete and report its findings in August 2013.

Our landscape study noted that overall the baselines showed limited use of peer review but generally positive responses and outcomes where it was used. It is therefore encouraging to see that many projects are taking forward aspects of peer collaboration in the assessment and feedback process.

At the University of Manchester the eFeP project is undertaking an evaluation of student peer-topeer feedback. Work is on going but initial results seem to suggest that peer-to-peer feedback is a valuable tool for raising both students' awareness of the feedback process and students' engagement with it. It is therefore envisaged that the peer-to-peer feedback exercise in modern languages will continue for the foreseeable future and opportunities to extend it are being investigated.

At Queen's University Belfast a number of schools are taking forward aspects of peer review including students 'marking' and discussing exemplar work from previous cohorts and the introduction of a peer-reviewed coursework element amounting to $10 \%$ of the summative assessment for a course that was previously $100 \%$ examination. 
Peer interaction was a key focus of the Student-Generated Content for Learning (SGC4L) project at the University of Edinburgh which aimed to evaluate the impact and educational effectiveness of using a free online tool (Peerwise) that permits cohorts of students to create, answer and discuss assessment questions they have created, across a range of undergraduate science courses. The evaluation concluded that the tool was effective in improving student attainment and that mid range students (as determined by a prior diagnostic test) benefited most from its use. The evaluation was not however able to draw any conclusions as to which aspect/s of the interactions were most effective: 'It is less clear whether this effect arises from authoring questions or from answering, rating and commenting on questions written by other students.' The study found that the workload associated with use of the tool was not onerous for staff and the project has published a briefing paper containing some good practice guidance as well as a full evaluation report. The project team noted one unintended consequence of their activities: 'Additionally, the project has provided evidence of a vein of student creativity that has, to date, largely gone untapped within these (and other) courses.'

\section{SUMMARY}

The projects in the assessment and feedback programme have not shied away from tackling difficult issues that lie at the heart of the learning experience. A strength of participating in a programme like this is that they are able to share and build upon a sound body of evaluation evidence and their data is making a valuable contribution to the research base in this area.

The discourse around underlying educational principles and values has been a strong unifying factor for many projects. It has enabled them to reconcile quite disparate views and, having achieved agreement on what they actually want to achieve, it becomes easier to establish whether or not a particular technology can help enhance the current situation.

The implementation of new technologies across organisations as large as colleges and universities is not without its technical challenges, particularly relating to integration with other institutional systems, but a major lesson emerging is that the fit with business processes is the key factor determining usability and take up.

The programme is producing some interesting models of stakeholder engagement, in particular, appreciative inquiry lines of approach are proving useful in gaining interest and involvement and peer networks are proving a valuable means of moving from early adoption to more widespread embedding.

It is too early to draw any overall conclusions from the programme but the signs are that the projects are moving on a fairly consistent technology-supported, trajectory through the assessment and feedback landscape and that their actions on the journey have the potential to have a transformative effect on many parts of that landscape.

\section{REFERENCES}

Boud, D., \& Molloy, E. (2012). Rethinking models of feedback for learning: the challenge of design. Assessment \& Evaluation in Higher 1-15. http://dx.doi.org/10.1080/02602938.2012.691462

Ferrell, G. (2012a) A view of the Assessment and Feedback Landscape: baseline analysis of policy and practice from the JISC Assessment \& Feedback programme. Available at: http://www.jisc.ac.uk/media/documents/programmes/elearning/Assessment/JISCAFBaselineReport May2012.pdf

Ferrell, G. (2012b) Moving out of base camp: an update on key themes from the Jisc Assessment and Feedback programme. Available at: http://repository.jisc.ac.uk/5082/

Hughes, G., Okumoto, K. and Crawford, M. (2010) Use of ipsative assessment in distance learning. Available at: http://cdelondon.wordpress.com/2010/07/28/use-of-ipsative-assessment-in-distancelearning/

Williams, J. and Kane, D. (2009). "Assessment and feedback: Institutional experiences of student feedback, 1996 to 2007." Higher Education Quarterly 63(3): 264-286. 


\section{AUTHORS' BIOGRAPHIES}

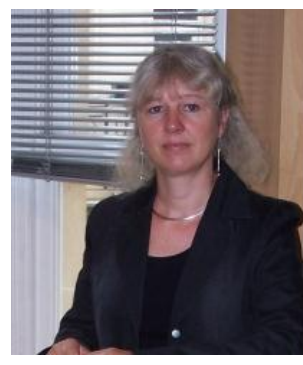

Gill has teaching and research experience and has held senior management positions in a number of university administrative functions as well as directing a UK support service enhancing the use of ICT in further and higher education. She acts as a consultant to universities and national agencies in both the UK and Europe and has been an invited speaker at many national and international events. Current interests include: data and information management, technology enhanced learning, assessment and feedback and learning space design.

http://uk.linkedin.com/in/gillferrell

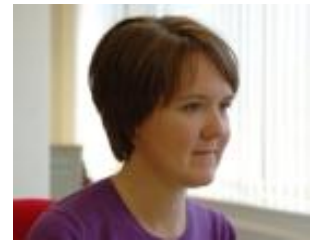

Marianne is an information professional with extensive experience of working in higher education and local government which has led to her current role as Researcher/Analyst at Jisc infoNet. Her primary experience has involved researching and managing information in different contexts including international and EU relations, faculty administration, development/Alumni relations and university marketing. Specialties: research, information management, CRM, project management, writing, project support, event management.

http://uk.linkedin.com/in/marianne.sheppard 